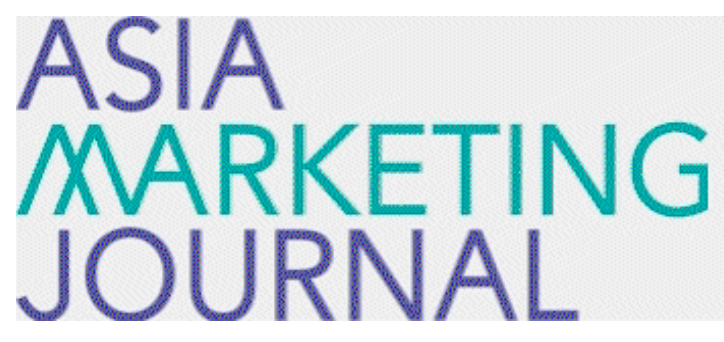

ASIA MARKETING JOURNAL

Volume 14 | Issue 3

Article 3

10-30-2012

\title{
The Effects of Hot Temperature on Impulsive Behaviors
}

Hee Kyung Ahn

Follow this and additional works at: https://amj.kma.re.kr/journal

Part of the Marketing Commons

\section{Recommended Citation}

Ahn, Hee Kyung (2012) "The Effects of Hot Temperature on Impulsive Behaviors," Asia Marketing Journal: Vol. 14 : Iss. 3 , Article 3.

Available at: https://doi.org/10.53728/2765-6500.1488

This Article is brought to you for free and open access by Asia Marketing Journal. It has been accepted for inclusion in Asia Marketing Journal by an authorized editor of Asia Marketing Journal. 


\section{The Effects of Hot Temperature on Impulsive Behaviors: The Role of Product Types as a Moderator}

Hee-Kyung Ahn*

Temperature and weather are all around us, quite literally. Furthermore, temperature and weather not only permeate our atmosphere, constantly affecting our visceral states of warmth and coldness, but they metaphorically permeate our language. People, products, and ideas can all be "hot" or "cold," Given this ubiquity, it is perhaps surprising that relatively little research has systematically examined the influence of temperature on choice and judgment. Temperature-related words such as "hot" and "cold" are often used to describe impulsive and calculated behaviors, respectively. These metaphoric connotations of thermal concepts raise the question as to whether temperature, psychological states and decision making are related to each other, and if so, how. The current research examines these questions and finds support for a relationship. Across one field study and one laboratory experiment, I demonstrate that both hot ambient room temperature ( $\mathrm{Spa}$ ) and hot temperature primes (words) trigger decision outcomes in line with the metaphoric association between hot temperature and impulsivity.

In the field study, participants were recruited in hot (40-50 degrees Celsius) and cold (10 degrees Celsius) rooms at a spa. Participants were simply asked to indicate their willingness-to-pay (WTP) for three product categories (travel package, birthday dinner, and cell phone). The results showed that participants in the hot room in comparison to those in the cold room were willing to pay more for the same products.

Next, I tested if our results would go beyond ambient temperature and would hold if I were to prime temperature concepts by using a different priming method (i.e., subliminal vs, supraliminal). In line with the previous findings in the spa, participants in the hot priming condition were more likely to choose the wrong answer for the bat and baseball question than those in the cold priming condition. In addition, product type (e.g.. pleasure vs. necessity) can moderate the effect of hot temperature on impulsivity. Mood and arousal did not mediate participants' responses. My findings seem to suggest that the effects of temperature on decision outcomes can be attributed to metaphoric associations rather than incidental mood or arousal.

The current research applies a novel perspective in understanding the relationship between temperature and judgment and decision making. Also, the results have practical implications for packaging, advertising, merchandising, and pricing of goods and services, as well as for public policy and awareness. One of

* Assistant Professor of Marketing, School of Business, Hanyang University (hkahn (ahanyang,ac,kr) 
the most natural implications of my findings would be that retailers would be better off carrying more impulse purchase items on hot days. Furthermore, point-of-purchase promotions encouraging impulse purchase is more likely to be effective in retail environments with higher temperature than with lower temperature. In addition, advertisements and product packages evoking hot temperature associations (e.g.. beach, sunshine, summer) might lead consumers to pay higher price for the advertised product than those with cold temperature associations.

Key words: impulsivity, temperature, metaphor, embodied cognition, priming

Most people, at some time or another, engage in impulsive behaviors in their judgments and choices. For example, we confront situations where we end up with extra purchases while shopping due to sudden impulses. As dieters, we sometimes yield to temptations (desires) for more chocolates without thinking of negative consequences. Similarly, a student may decide to go to a party tonight even if he/she has to prepare for an exam scheduled in a few days. Such unreflective behavioral tendencies or a lack of self control due to a sudden desire or urge could result in impulsive behaviors in various domains. Impulsivity has been widely studied in a variety of disciplines including cognitive, clinical, social, developmental, and consumer psychology, economics, and judgment and decision making in general. Although previous research has covered a wide range of impulsive behaviors (Eysenck and Eysenck 1978: Monterosso and Ainslie 1999: Puri 1996: Rook and Fisher 1995), it is rather surprising that there is limited research that identifies specific conditions under which impulsive behavioral tendencies are stronger or weaker. Some researchers have shown that visceral stimuli (e.g., exposed rewards, sexual and appetitive cues) increase desire and engender impatience (Baumeister 2002: Bergh, Dewitte, and Warlop 2008: Hoch and Loewenstein 1991: Li 2008) by demonstrating individuals' preference for immediate (vs. delayed) rewards triggered by those external cues.

In our daily lives, temperature-related words such as "hot" and "heat" are often used to describe such impulsive behaviors (e.g.. hot headed). In these expressions, "hot" is interpreted as a metaphor rather than as a literal thermal concept. In addition, marketers often use different temperature associations to build up their brands in various marketing contexts such as advertising, packaging and retailing. For example, consumers are exposed to different gum brands which can evoke distinct temperature associations (e.g.. Excel Inferno, Excel Polar Ice). Can these temperature related words influence subsequent choices and judgments? Particularly, it might be an interesting question whether marketing stimuli that suggest hot temperatures 
can actually induce impulsive behaviors.

Although there has been relatively little research that systematically examines the relationship between temperature and decision making. psychologists and behavioral decision researchers often use the thermal concept "hot" (vs. "cold") to describe impulsive behaviors metaphorically (Loewenstein 1996: Metcalfe and Mischel 1999: Peters et al. 2006). These metaphoric associations of thermal concepts and impulsivity raise the question as to whether temperature concepts, psychological states, and decision making are related to each other, and if so, how.

While previous research on impulsive behaviors used external stimuli that can directly change people's visceral states (e.g., appetitive cues). the current research investigates whether priming hot temperature related concepts can trigger impulsive behaviors. By examining the effects of priming merely the concept of temperature on impulsivity. I attempt to build upon prior research which has demonstrated the direct effects of visceral cues on impulsivity. Specifically. I demonstrate that the association between the thermal concept 'hot' and impulsivity is not simply metaphorical, but that activating the concept of hot can actually cause impulsive behaviors. By using different priming manipulations of the concept of temperature as well as various dependent measures to operationalize the concept of impulsivity, I provide a controlled demonstration of the causal effects of priming temperature on behavior. This is consistent with my proposition that the mere priming of 'hot' can activate its metaphorically linked concepts such as desire, urge or drive, which in turn, lead to impulsive behaviors.

\section{Various Manifestations of Impulsivity}

Individuals often act without considering the full consequences of their actions. These actions, based on feelings, focus on immediate pleasures rather than on long-term consequences, which often result in complications. For instance, people often succumb to the temptation of dessert, alcohol, cigarettes or drugs, opting for immediate gratification without thoughtful consideration of the associated long term risks (Hofmann, Friese, and Wiers 2008). Previous research demonstrated that many consumption behaviors can be framed in terms of a conflict between immediate impulses on one hand and reasoned attitudes and standards to restrain behavior on the other (e.g., Baumeister and Heatherton 1996: Carver 2005).

Although it is easy to identify examples of impulsive behavior in both the literature and in our everyday lives, it is difficult to rigorously define what constitutes impulsive behavior, especially in the context of different cultures and ages, leading to a great amount of disagreement regarding the definition of the term (Evenden 1999). As a lexical definition, however, the 
word 'impulsive' is described as "inclined to act on impulse rather than thought" (The American Heritage Dictionary of the English Language 2000) or "characterized by actions based on sudden desires, whims, or inclinations rather than careful thought" (Collins English DictionaryComplete and Unabridged Sixth Edition 2003). Evenden (1999) specifically pointed out, "There is not one unitary 'impulsivity' or only one type of impulsive behavior. Instead, there are several related phenomena which are usually classified together as impulsivity, which I would like to term 'varieties of impulsivity,' and which leads to different forms of impulsive behavior" (p. 348). The term impulsivity has been used in the literature to represent a number of different behaviors. In studying it, it is important to recognize that impulsivity is multidimensional and does not manifest itself as a single trait or construct (Romer 2010). Some researchers in psychology define impulsivity as the inability to delay gratification or the inverse of self-control (Ainslie 1975: Metcalfe and Mischel 1999: Monterosso and Ainslie 1999), while others define impulsivity as "short decision time" or "lack of persistence" (Buss and Plomin 1975), "unconscious risk taking" (Eysenck 1993), and "sensation seeking" (Zukerman 1994). Barratt (1985) characterized impulsivity as the inability to plan ahead, acting without thinking, fast speed of response, and risk taking (Langewisch and Frisch 1998). Particularly Frederick (2005) argued that the prevalence of an erroneous but intuitive answer (i.e., "10 cents") to the "bat and baseball problem' is due to impulsivity characterized by immediacy of responses and short decision times, suggesting that impulsivity causes people to respond with the first thing that comes to mind. A comprehensive review of the impact of the hot-impulsivity link on judgment and decision making requires that we rigorously define the concept of impulsivity. Therefore, I conceptualize the construct of impulsivity as used in the current research, and discuss the focal manifestations of impulsivity that will be dealt with in the empirical part of the paper.

Many consumer researchers have dealt with the concept of impulsivity in buying or spending situations. Impulsive buying behavior can be interpreted by the core elements of impulsivity. For example, Kacen and Lee (2002) stated. "impulsive buying behavior is a sudden, compelling, hedonically complex purchasing behavior in which the rapidity of the impulse purchase decision process precludes thoughtful, deliberate consideration of all information and choice alternatives." In addition, impulsive buying can be viewed as involving spontaneous and unreflective desires to buy, without carefully considering the reason for the purchase (Rook 1987: Rook and Fisher 1995: Vohs and Faber 2007).

Rook and Hoch (1985) explain impulsive purchasing as being accompanied by a "sudden and spontaneous desire to act" (p. 23) "without regard to the consequences" (p. 24), which implies that impulse purchases can be understood as a 
consumer's pursuit of immediate gratification. In particular, a recent study by Vohs and Faber (2007) demonstrates that depleted self-regulatory resources during buying situations lead to a higher willingness to pay (WTP) for potential purchases. The findings suggest that when a consumer's desire to buy is intensified by exerting regulatory resources in an initial self-control task (i.e., temporal depletion of self-regulatory resource), he/she may be less able to resist the impulse to buy, and hence induce higher willingness to pay for products/services. In other words, consumers are willing to pay more for target products or services caused by their increased desire without thoughtful consideration. Impulse buying or spending situations with higher willingness to pay for products or services is due to a lack of self control (Vohs and Faber 2007), which is often caused by a lack of deliberation.

Secondly, in numerous research papers, the concept of impulsivity is characterized by short decision times (Buss and Plomin 1975) or fast responses (Barratt 1985) mainly due to a lack of thoughtful consideration. According to another measure of impulsivity by Porteus (1965), a scoring system was based on the participant's lack of attention to detail, carelessness and lack of planning, depicted by errors in solving mazes. Extending these process-based explanations, a large body of literature has addressed the distinction between two types of cognitive processes: quick, less deliberative processes and slower, more reflective processes (Epstein 1994:
Kahneman and Frederick 2002: Stanovich and West 2002). With this in mind, consider the following problem:

A bat and a baseball cost $\$ 1.10$ in total. The bat costs $\$ 1$ more than the ball. How much does the ball cost?

Here, an intuitive and impulsive response (e.g.. 10 cents) can spring to mind when answering the bat and baseball problem based on the quick, less deliberative processes. Frederick (2005) argued that the prevalence of an erroneous but intuitive answer to the bat and baseball problem (i.e., '10 cents' instead of the correct answer, '5 cents') is due to immediate impulses (see also Kahneman 2003). Kahneman (2003) explained that this erroneous answer is due to the fact that the sum $\$ 1.10$ simply separates into $\$ 1$ and 10 cents. Although the simple mathematical calculation may require a minimum level of cognitive effort, this apparently fast and automatic response based on the simple calculation (i.e., system 1) can be attributed to impulsivity (Kahneman 2003).

However, not all problem solving tasks engender such an immediate and impulsive reaction. As Frederick (2005) exemplifies, finding the square root of 19163 to two decimal places without a calculator involves slower, reflective mental operations requiring effort, motivation, concentration, and the execution of learned rules. In addition, quick, less deliberative processes are less likely to play a role in yielding incorrect answers in a domain of purely knowledge based problems (e. g. quizzes for historical facts). It is important 
to note that for the bat and baseball problem. individuals who are mathematically sophisticated are likely to answer correctly. In addition, individuals who are highly motivated may reflect upon the structure of the question carefully, and are therefore more likely to respond correctly. However, individual differences in terms of ability and motivation are outside of the focus of the current research, and random assignment of participants should balance highly motivated and mathematically sophisticated participants across conditions.

In summary, although impulsivity is not a simple, unidimensional construct, it seems that the concept needs to be broadly defined as a behavioral tendency characterized by several elements. In the current research, I take into consideration a variety of manifestations of impulsivity adopted by researchers across disciplines, and I conceptualize impulsivity as an unreflective behavioral tendency or a lack of self-control due to a sudden desire or urge that could result in undesirable (negative) outcomes. Based on this conceptualization of impulsivity, I operationalize impulsive behaviors as a higher willingness to pay due to an unconsidered valuation, and an erroneous response to the bat and baseball problem.

Given this operational definition of impulsivity, the next step is to examine whether and how the concept of impulsivity could be related to temperature. As previously discussed, I argue that the concept of impulsivity and temperature are related to each other in a metaphorical fa- shion, and understanding this metaphorical relationship plays an important role in investigating the impact of priming temperature on impulsivity. In the next section, I review relevant literature on embodied cognition perspectives, and the metaphoric link between 'hot' and impulsivity.

\section{Embodied Cognition Perspective}

Traditional views of cognitive psychology have characterized the mind as an abstract information processor that is independent of the body and the environment (Beilock and Holt 2007). However, recent theories of embodied cognition suggest that cognitive representations and operations are fundamentally grounded in their physical context and perception (Barsalou 1999; Gallese and Lakoff 2005: Glenberg 1997: Lakoff and Johnson 1999). Researchers who have examined metaphors have found that some metaphoric associations can be understood with the theory of embodied cognition (for an overview, see Barsalou 2008). This theory postulates that cognitive representations are rooted in the brain's sensorimotor systems. Perceptual representations of abstract concepts (i.e. target domains) are developed through the individual's mapping of experienced bodily states (i.e. source domains). The actuation of these bodily states can affect abstract thinking and mental stimulation. Abstract concepts are learned through the 
repetition of physical experiences in childhood. According to one of the recent findings in embodied cognition (Jostmann, Lakens, and Schubert 2009), when people hold a heavy object (i.e.. physical weight) this bodily experience influences their judgment of the importance of an issue in an unrelated domain. Particularly, in one experiment, participants were asked to estimate the value of foreign currencies while holding a heavy or a light clipboard. Participants who were holding a heavy clipboard placed a higher value on these foreign currencies than those who were holding a light clipboard. According to the author, value is a crucial index of a currency's importance. That more strength or strategizing is needed to handle weighty objects than light ones, for instance, is learned by handling objects physically (Jostmann et al. 2009). Therefore, people link the experience of heaviness with a heightened degree of physical and intellectual exertion. In this instance, the separate domains of physical heaviness and significance share the same relational structure, and therefore, such a cross-domain mapping can occur.

\subsection{Metaphoric Link between 'Hot' and Impulsivity}

Most people are acquainted with the concept of temperature. In addition to denoting a physical phenomenon, temperature has also generated a large number of metaphors. The terms "hot" or "cold" are applied to a wide variety of things, including ideas, individuals and commodities. Calculated conduct is frequently termed "cold," just as impulsive behavior is regularly labeled "hot." Metaphors linking hotness and impulsivity are especially common in everyday life (e.g., "hot-headed, impulsive murder': see Bushman and Anderson 2001). "Hot" is understood metaphorically rather than physically in these expressions. For instance, the terms "hot-headed' and 'impulsive' are regarded as interchangeable and lexically synonymous. Moreover, different mental states have been depicted metaphorically with temperature-related words in academic research. For example, the hot-impulsive system has been contrasted with the cold-reflective system. That 'hot' has an impulsive characteristic has also been shown by earlier research based on the hot-cool framework (Metcalfe and Mischel 1999). However, rather than treating 'hot' as a physical concept that genuinely motivates impulsive conduct, researchers have merely deployed the word 'hot' as a metaphor for impulsive traits such as hasty information processing.

In addition to psychologists, many behavioral decision researchers have utilized the thermal concept of 'hot' to portray impulsivity (Loewenstein 1996: Peters et al. 2006) by contrasting the thermal concept of hot with cold. They often use the thermal concepts of hot and cold to describe human beings' distinct mental processing systems such as emotion and cognition respectively. Their efforts have been in keeping with the theory that individuals typically use metaphors 
to think of abstract concepts in physical ways (Amorim, Isableu, and Jarraya 2006: Lakoff and Johnson 1980). As remarked by Lakoff and colleagues, metaphors signify abstract domains for people. Hence, terms related to temperature, which is a concrete domain, are used to depict impulsivity, a more abstract domain.

Overall, I suggest that the conceptualization of impulsivity can be embodied by the priming of hot temperature as a simulation of the bodily state. In other words, embodied cognition states that the simulation of a concrete concept (i.e., hot) can be associated with an abstract concept (i.e., impulsivity), which is in line with the cross mapping of two disparate domains in metaphors. The term "embodied" cognition can create some confusion. A common misunderstanding related to "embodied cognition" is that bodily states are necessary for cognition, and as a result, researchers focus heavily on bodily states in conducting research. However, according to Barsalou (2008), "cognition often proceeds independently of the body, and many researchers address other forms of grounding. Grounded cognition reflects the assumption that cognition is typically grounded in multiple ways including simulations, situated action, and on occasion, bodily states (p. 619)." In particular, I explore the often-used metaphorical association between the thermal concept 'hot' and impulsivity and test whether both (1) actual (physical) experiences of 'hot' temperature as well as (2) the simulation of these experiences through primes can elicit impulsive behaviors.

\section{Field Study}

In order to explore the link between ambient temperature and impulsive behaviors, I conducted a field study at a spa in Seoul, South Korea. Forty-four participants were recruited at the spa, and were compensated with souvenir gifts. The spa had rooms varying in temperature, and two rooms were selected: one hot and one cold. The cold condition was employed for comparison purposes. The reason that I did not include the neutral temperature condition in my field study was because there was no temperature-neutral spa room at the spas. Although most spas in Korea have a temperature-neutral hall area where spa visitors can watch TV and eat snacks, I thought that the hall area is very different from the spa room in terms of its environment (ambience) such as people's levels of distraction and the room size. The temperatures of the hot and cold rooms were $40 \circ \mathrm{C}-50^{\circ} \mathrm{C}$ and $10^{\circ} \mathrm{C}$, respectively. For three product categories (travel package, birthday dinner, and cell phone), participants in each room were asked to indicate their willingness to pay on a seven-point scale anchored by amounts in the Korean currency, Won (KRW), divided by 10,000 . The sevenpoint scale ranged from low to high prices, (travel package: KRW 40 -100: dinner: KRW 2-8: cell phone: KRW 20-50). For example, for the travel package, the willingness to pay question presented participants with a seven- 
point scale (Nelson and Simmons 2009) anchored at 40 on the low end, and then increasing in increments of 10 to 100 .

Next, participants were asked to fill out a questionnaire regarding their spa usage habits (frequency of visit, average hours per visit, and preference for room temperature). All participants in each room had spent at least 10 minutes in it before answering the questions. This was to ensure that they had adapted to the particular room temperature (i.e., hot or cold).

The willingness to pay for the three products was consistently higher in the hot room ( $M_{\text {travel }}$ package $=88.57, \mathrm{SD}=11.53: M_{\text {dimner }}=6.00, \mathrm{SD}=$ 1.41: $\left.M_{\text {cellular phone }}=43.33, \mathrm{SD}=8.42\right)$ than in the cold room $\left(M_{\text {travel package }}=70.43, \mathrm{SD}=11.47\right.$ : $M_{\text {dinner }}=3.96, \mathrm{SD}=1.02: M_{\text {cellular phone }}=37.39$, $\mathrm{SD}=7.05)$. These differences were statistically significant [travel package, $t(42)=5.23, p<$ .001 : dinner, $t(42)=5.53, p<.001$ : cellular phone, $t(42)=2.55, p<.05]$. The results of the field study support my prediction that consumers exposed to hot ambient temperature as opposed to cold temperature might behave more impulsively.

\section{Experiment}

In this experiment, I test whether priming temperature concepts can induce the same effect as in the spa. In doing so, I use a scram- bled sentence test (Srull and Wyer 1979) in the supraliminal priming condition and a lexical decision tack in the subliminal priming condition (Dijksterhuis, Preston, Wegner, and Aarts 2008: Strahan, Spencer, and Zanna 2002). In order to check whether hot temperature primes induced participants to actually feel hot, I compared participants' felt temperature on a seven-point scale across the two conditions and measured participants' estimates of the room temperature. However, there is a possibility that participants' self-reporting of felt temperature on a sevenpoint scale (e.g., how do you feel? 1-cold, 7-hot), measured immediately can be simply attributed to demand artifacts in the supraliminal priming condition, and participants in the hot priming condition (hot related words) did not actually feel hotter. In addition to this possibility, in the supraliminal priming conditions, participants may have been consciously aware of the concept "hot,, and this awareness may have resulted in them actually feeling hot. Because of these reasons, I use a subliminal priming method employing a lexical decision task. Participants who are primed subliminally are not aware of the target concepts (hot, cold and neutral temperatures), thus completely eliminating the possibility of demand artifacts. By then measuring participants' perceived or felt temperatures, I can examine the possible mediating effects of feeling hot. I expect that if participants report that they are feeling hotter in the hot priming condition and I observe the effect of hot temperature primes 
on impulsivity, this may again indicate the mediating role of feeling hot in the hot-impulsivity pathway. If there is no difference in perceived or felt temperature across conditions and I still observe the effect of hot temperature primes on impulsivity, then feeling hot is not likely a mediator of the hot-impulsivity pathway.

In my previous field study, I did not systematically test under what condition the observed effect of hot temperature primes on willingness to pay is moderated. Rather, I adopted various product categories such as birthday dinners and cellular phones, and found the effects of hot ambient temperature on impulsivity in these categories. In this experiment, I examine whether there is a moderating role of product type (pleasure vs. necessity) in the effect of hot temperature primes on impulsivity.

Consumers' impulsive behavioral tendencies may be weak or strong depending on the nature of the target product categories. Individuals purchase goods or services for two basic reasons: (1) consummatory affective (or hedonic) gratification from sensory attributes, and (2) instrumental, utilitarian reasons concerned with "expectations of consequences" from functional and non-sensory attributes (see Holbrook and Hirschman 1982). Hedonic goods are more likely to influence the sensory, imagery, and affective senses of the individual (Park and Kim 2010). For instance, Hsee and Rottenstreich (2004) describe hedonic goods as "affect-rich" goods, and utilitarian goods as "affect-poor" goods.
Furthermore, Mischel and Metcalfe (1999) have argued that impulsivity is related to affective senses, which exist only for affect-rich hedonic goods, and not for affect-poor utilitarian goods.

A question worth addressing is whether the effect of hot temperature primes on willingness to pay will hold for necessary household products for which the primary reason of purchase is not mainly based on hedonic pleasure. I test whether product type (e.g., pleasure vs. necessity) can moderate the effect of hot temperature on willingness to pay and expect that participants' willingness to pay for necessary household goods will not be significantly higher in the hot priming condition than in the other conditions (i.e., cold and neutral).

\subsection{Experimental Design}

\subsubsection{Participants}

One hundred and sixty two participants at the University of Toronto participated in this experiment in exchange for 5 Canadian dollars. In this experiment, I adopted three primes (hot, cold, and neutral) using two priming methods (supraliminal vs. subliminal) in a betweenparticipants design. All participants were randomly assigned to one of the six conditions.

\subsubsection{Stimuli and Procedure}

In all six experimental conditions, participants 
were told that they would be asked to complete two separate tasks: a language ability test followed by a general consumer preference survey. Participants in the supraliminal priming conditions were asked to do a scrambled sentence test. The scrambled sentence test consisted of 26 sets of five scrambled words (e.g., "people water cold clothes drink"), each of which, participants had to re-construct into a grammatically correct four-word sentence as quickly as possible (participants had to use four out of the five provided words). I designed three versions of the scrambled sentence test. One version was intended to prime the construct "hot", another primed the construct "cold", and the third version was intended to prime neither concept (temperature-neutral). In all three versions, 13 out of the 26 sentences contained an adjective, a noun, or a verb semantically related to the concept in question (e.g., hot prime: hot, sizzling, boiling, sunny: cold prime: freezing, snow, ice, cold: neutral prime: student, car, plan, responsibility) and the remaining 13 filler sentences contained only temperature-neutral words (e.g., philanthropist, performing, does).

For the participants assigned to the subliminal priming conditions, I adopted a computerized lexical decision task for priming target words. Identical prime (i.e., hot, cold, and neutral) and filler (masking) words were used in both the scrambled sentence test and the lexical decision task. All masking words were temperatureneutral (e.g., philanthropist, performing. does).
In the lexical decision task, the 13 prime words were presented for $20 \mathrm{~ms}$ (e.g., hot prime: hot, sizzling, boiling, sunny: cold prime: freezing, snow, ice, cold: neutral prime: student, car, plan, responsibility). Participants were asked to indicate whether a series of letter strings were a real word or a non-word by pressing the ' $\mathrm{Z}$ ' or ' $\mathrm{M}$ ' key, respectively. In each computerized session, 13 prime words and 13 mask words were presented alternately: however, due to the subliminal $20 \mathrm{~ms}$ presentation time of the prime words, participants only saw 13 mask words, and their task was to indicate whether each one was a word or not.

After completing the scrambled sentence test (i.e., supraliminal priming) or the lexical decision task (i.e., subliminal priming), participants were told that they had to complete a consumer survey questionnaire. Participants were told to indicate whether two statements were true or false. In this section, I used two questions. While the target question was the bat and baseball problem (i.e., "A bat and baseball cost $\$ 1.10$ in total. The bat costs $\$ 1$ more than the ball. So, the ball cost 10 cents."-True or False?), the other one was a filler question (i.e., "Conakry is the capital of French Guinea,"). The filler question was always followed by the target question. In addition, I included a question regarding willingness to pay. Participants were asked to indicate whether they would be willing to spend less, same as, or more than usual (by using a seven-point scale, anchored by 1 being 
less than usual, 4 being same as usual and 7 for more than usual) on pleasure/entertainment goods and necessary household goods in the current month (e.g., April).

Next, participants were asked to indicate the felt temperature by answering how they feel on a seven point scale, anchored from 1 (cold) to 7 (hot). In addition, I asked participants to estimate the ambient room temperature (in degrees Celsius). Finally, they were asked to indicate the pleasantness of the room temperature on a seven-point scale anchored froml (not pleasant at all) to 7 (very pleasant). Participants also rated their mood (bad - good, disappointed - satisfied, sad - happy, displeased - pleased) and level of arousal (calm - excited, down - elated, tired - energetic, sedated - aroused) on 17-point scales anchored at -8 and 8 (Salovey and Birnbaum 1989). The mood and arousal measures were to be used in the analysis intended to rule out alternative pathways that operate via mood and arousal.

\subsection{Results and Discussion}

\subsubsection{Choice of an Impulsive Option (Error Rates)}

I analyzed the choice data by using binary logistic regression models predicting the choice (i.e., choice of 'False') as a function of priming type (supraliminal vs. subliminal), temperature (hot, cold, and neutral), and their interactions.
Binary logistic regression analyses showed that overall, priming type, temperature, and their interactions do not predict impulsivity (bat and baseball: $\left.x^{2}(5)=6.84, p>20\right)$. Since I did not find an statistically significant interaction between temperature and priming type, and the focus of analysis was the differential impact in the three thermal conditions, I first used a one-factor (i.e., temperature) binary logistic regression model for the bat and baseball problem by collapsing the data across the two priming type conditions (i.e., supraliminal and subliminal). One marginally significant result emerged regarding the bat and baseball question, to which participants were more likely to choose an erroneous answer in the hot priming condition than in the neutral priming condition $(\beta=.76$, $p=.059$ ). Specifically, $48.1 \%$ (26 out of 54 ) of participants answered incorrectly in the hot priming condition, whereas $30.2 \%$ (16 out of 53 ) of participants in the neutral priming condition chose the incorrect answer $\left(x^{2}(1)=3.62, p=\right.$ .057). The error rate in the cold priming condition $(41.8 \%)$ was not significantly different from that in the neutral priming condition $[30.2 \%$ : $\left(x^{2}(1)=1.58, p>.20\right)$. This result implied that the observed impulsive behaviours are due to the hot-impulsivity link but there is no impact of the cold-calculated link.

Next, I examine the difference between the supraliminal and subliminal conditions for the bat and baseball problem in detail. Although there was neither a significant main effect nor 
a significant interaction effect involving priming type, a binary comparison between the hot and neutral conditions revealed an unexpected interesting result. As figure 7.1 shows, the higher error rate in the hot (vs. neutral) priming condition is mainly driven by the difference in the subliminal priming condition. In the subliminal/ hot priming condition, $55.2 \%$ (16 out of 29) of participants gave incorrect answers to the bat and baseball question, whereas only $31.0 \%$ (9 out of 29) of participants in the neutral priming condition offered the incorrect answer. The difference is marginally significant $\left(x^{2}(1)=3.45\right.$. $p=.063$ ). For the supraliminal priming condition, however, the error rate in the hot priming condition (40.0\%: 10 out of 25$)$ is not significantly higher than in the neutral priming condition $\left[29.2 \%: 7\right.$ out of $\left.24,\left(x^{2}(1)=.63, p>.40\right)\right]$.

〈Figure 1> Influence of Priming Type and Temperature on Error Rate of the Bat and Baseball Problem: Experiment 4

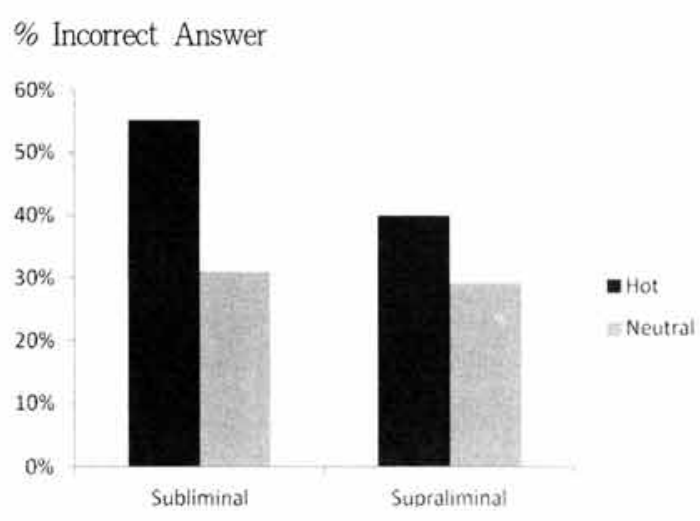

\subsubsection{Willingness to Pay Measure}

In this experiment. I included a different question to measure participants' willingness to pay. Participants were asked to indicate whether they would spend less, same as, or more than usual (a seven-point scale, anchored by 1 being less than usual, 4 being same as usual and 7 for more than usual) on pleasure/entertainment goods and necessary/household goods. I expected that the effect of priming hot on willingness to pay may be qualified by the product type (i.e., pleasure vs, necessity). To examine the answers to this question, I conducted a mixed design ANOVA. Product type was a within-participants variable and temperature (i.e., cold vs. neutral vs. hot) and priming type (i.e., supraliminal vs. subliminal) were between-participants variables.

For the test of within-participants effects, I did not find a significant interaction among product type, temperature and priming type $(F(2,155)=1.97, p>.10)$. In addition, the interaction between product type and priming type was not statistically significant $(F(1,155)$ $=2.30, p>10$ ). However, as I expected, there was a significant interaction between product type and temperature $(F(2,155)=3.76, p<$ $.05)$. Specifically, for the pleasure and entertainment goods, participants reported that they were going to spend significantly more than usual in the hot priming condition than in the other two priming conditions $\left[M_{\text {hot }}=4.41 . \mathrm{SD}=\right.$ $1.31: M_{\text {neutral }}=3.66, \mathrm{SD}=1.74: M_{\text {cold }}=3.78$, 
$\mathrm{SD}=1.45: F(2,156)=4.22, p<.05]$, while there were no significant differences in the scores across all three priming conditions for the necessity goods $\left[M_{\text {hot }}=3.93, \mathrm{SD}=1.03: M_{\text {neutral }}\right.$ $=3.96, \mathrm{SD}=1.02 ; M_{\text {oold }}=4.06, \mathrm{SD}=1.02$ : $F(2,155)=.39, p>60]$. Figure 2 shows the two-way interaction between product type and temperature.

\section{〈Flgure 2〉 Influence of Temperature Primes on} WTP for Pleasure and Necessity

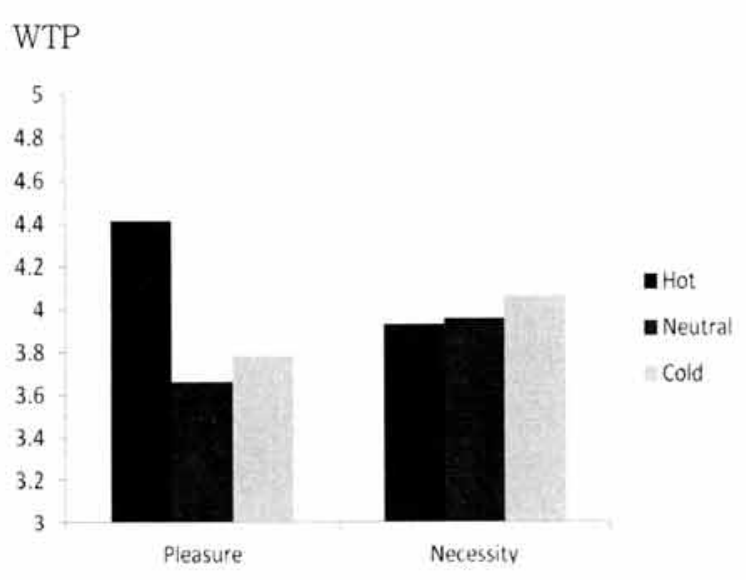

For the tests of between-participants effects. there was a marginally significant main effect of priming type on willingness to pay $\left[M_{\text {sublininal }}\right.$ $=3.85, \mathrm{SD}=1.29: M_{\text {supraliminal }}=4.10, \mathrm{SD}=$ 1.23: $F(1,155)=2.90, p=.09]$ and a marginally significant main effect of temperature on willingness to pay $\left[M_{\text {hot }}=4.17, \mathrm{SD}=1.17\right.$ : $M_{\text {neutral }}=3.81, \mathrm{SD}=1.38: M_{\text {cold }}=3.92, \mathrm{SD}$ $=1.23: F(2,155)=2.37, p=.097]$. For the main effect of priming type on willingness to pay. I speculate that there was an unexpected stronger priming effect. Although I tried to use the same words in both priming conditions, participants in the supraliminal condition were exposed to target words with no time limit (i.e., they were allowed to spend time as much they wanted). The differential exposure time between the supraliminal and subliminal priming conditions may have driven this effect. Posthoc analyses confirmed that this main effect of temperature on willingness to pay is driven by the difference between hot and neutral priming conditions [least significant difference (LSD), $p<.05]$.

\subsubsection{Felt Temperature and Temperature Estimates.}

Next, I conducted a two-way (priming type by temperature) ANOVA with felt temperature and temperature estimates as a dependent variable respectively. There were no significant interactions between priming type and temperature across two measures [felt temperature: $F(2,156)=.15, p>.80:$ temperature estimates: $F(2,156)=.76, p>.40]$.

Finally, I found that felt temperatures across three temperature conditions were not significantly different $\left(M_{\text {oold }}=4.24, \mathrm{SD}=.77: M_{\text {neutral }}\right.$ $=4.36, \mathrm{SD}=.86: M_{\text {hot }}=4.35, \mathrm{SD}=.80$ : $F(2,156)=.42, p>.60)$. Also, participants estimates of the room temperature were not significantly different across the temperature conditions $\left(M_{\text {cold }}=19.9^{\circ} \mathrm{C}, \mathrm{SD}=7.43: M_{\text {neutral }}\right.$ 
$=21.3{ }^{\circ} \mathrm{C}, \mathrm{SD}=3.37: M_{\text {hot }}=21.1{ }^{\circ} \mathrm{C}, \mathrm{SD}=$ 4.25: $F(2,156)=.84, p>.40)$. The results regarding both measures of felt temperature and temperature estimate showed that participants in the hot priming condition were not feeling hotter than the other two conditions, which indicates that participants' actual feeling hot is not necessary to engage in impulsive behavior as manifested in higher willingness to pay for pleasure/entertainment goods in the hot priming condition. I thought felt temperature (e.g.. how do you feel?) was a relatively more subjective judgment than a temperature estimate, although I admit that the temperature estimate may also be based on participants' subjective perception about the room temperature. In addition, as mentioned, measuring felt temperature after priming the concept of temperature can result in demand artifacts. However, participants were asked to estimate the room temperature for the building manager's use. Therefore, without participants' awareness of a relationship between temperature priming and estimated temperature. I was able to measure their perceived temperature by asking the room temperature estimates while minimizing the influence of demand artifacts.

\subsubsection{Mood, Arousal, and Pleasantness of Room Temperature}

I conducted 3 two-way (priming type by temperature) ANOVAs with mood, arousal and pleasantness of the room temperature as the dependent variables, respectively. There were no significant interactions between priming type and temperature [mood: $F(2,156)=1.58, p>$ $.20:$ arousal: $F(2,156)=69, p>.50$ : pleasantness of the room temperature: $F(2,156)=$ $.44, p>60]$.

As I expected, both the average mood score (Cronbach's $a=.92$ ) and the average arousal score (Cronbach's $a=.71$ ) were not significantly different across the hot, neutral, and cold priming conditions (mood: $M_{\text {cold }}=2.85$, $\mathrm{SD}=2.62: M_{\text {neutral }}=2.76, \mathrm{SD}=3.43: M_{\text {hot }}$ $=3.44, \mathrm{SD}=2.67: F(2,156)=1.02, p>.30$ : arousal: $M_{\text {cold }}=-.40, \mathrm{SD}=2.43 ; M_{\text {neutral }}=.11$, $\mathrm{SD}=2.45: M_{\text {hot }}=-.02 . \mathrm{SD}=2.21: F(2,156)$ $=.68, p>.5)$. Thus, the significantly higher willingness to pay for the pleasure/entertainment goods and the higher error rate in the hot priming condition compared to the other priming conditions cannot be explained by participants' mood and arousal. Consistent with the mood data, the measure of pleasantness of the room temperature were not different across three temperature conditions $\left(M_{\text {cold }}=5.15, \mathrm{SD}=1.46\right.$ : $M_{\text {peutral }}=5.00, \mathrm{SD}=1.47: M_{\text {hot }}=5.17, \mathrm{SD}=$ 1.13: $F(2,156)=.29, p>.70)$.

Finally, there were no main effects of priming type on mood $\left[M_{\text {subliminal }}=3.19, \mathrm{SD}=2.92\right.$ : $M_{\text {cupraliminal }}=2.82 . \mathrm{SD}=2.94: F(1,156)=.70$. p) .40$]$ and arousal $\left[M_{\text {subbirinal }}=-.07, \mathrm{SD}=\right.$ 2.36: $M_{\text {supraliminal }}=-.15, \mathrm{SD}=2.38: F(1,156)$ $=.05, p>80]$. Also, pleasantness of the room temperature was identical regardless of priming 
type $\left(M_{\text {subbiminal }}=5.11, \mathrm{SD}=1.30: M_{\text {supralininal }}\right.$ $=5.09 . \mathrm{SD}=1.43: F(1,156)=.01, p>.90)$.

Priming hot temperatures triggered impulsive judgment/choice without the mediating influence of participants actual feeling hot (e.g., the error rate of answering the bat and baseball question in the subliminal priming condition and the willingness to pay for pleasure/entertainment products regardless of the type of priming). All in all, these results seem to lend support to the proposition that the effect of priming hot temperature on impulsive behaviors is not mediated by participants" actual feeling 'hot'. It seems important to note that the impact of priming hot temperature on impulsive behaviors was demonstrated in the subliminal priming condition as well.

\section{General Discussion}

\subsection{Summary of Findings and Implications}

The current paper examines the influence of ambient temperature and priming temperature on judgment and decision making. Specifically, I found that temperature primes may have an influence on decision outcomes, possibly due to the link between temperature concepts and impulsivity. Second, the type of products moderates the effect of hot temperature on impulsive be- haviors. Third, the effect of hot temperature primes is not mediated by individuals actually feeling hot, their moods or states of arousal.

The current research contributes to the understanding of the influence of priming temperature concepts on judgment and choice. First, recent work on the effect of temperature and weather has focused on actual temperature and its direct consequences (mood, cognition, and behaviors). The findings in this research take this insight a step further by demonstrating a metaphoric link between temperature concepts and impulsivity.

Second, my findings complement studies on the relationship between physical temperature and personality evaluation (Williams and Bargh 2008). Williams and Bargh (2008) demonstrated that incidentally touching warm or cold objects (i.e., actual experience of temperature) influences the assessment of traits in other people. I demonstrate that both ambient temperature and temperature primes (simulations of physical temperature experience) can influence subsequent choices and judgments outside of the social domain. These findings are consistent with the theories of embodied cognition - processing of abstract concepts involves embodiment, where embodiment refers both to actual bodily states and simulations of experience in the brain's modality-specific systems for perception, action, and introspection (Neidenthal et al. 2005).

The results have practical implications for packaging, advertising, merchandising, and pricing of goods and services, as well as for public 
policy and awareness. Many forms of marketing communication such as packaging, advertisements, and promotions can be presented to consumers with different associations of temperature. For instance, pictures of summer or hot-temperature related content (e.g., beach, sunshine, red color) in ads or on packaging might prompt a consumer to choose a more expensive brand or product.

In addition, the type of product or service that companies provide would result in different marketing strategies. If the product or service is more hedonic or pleasure oriented, as the findings of the experiment suggest, hot temperature associations are more effective in inducing consumers' impulsive buying intentions. In real world settings, however, there may be other factors that interact with primed temperature to influence impulse purchase. Finally, the findings from the current research have important implications for public policy. Public advertising intended to reduce the usage level of illegal drugs or cigarettes, to give warning signals, often use colors (e.g., red) or words (e.g., could burn your head') that may activate the hot temperature association. These advertisements may have unintended consequences, such as promoting rather than preventing the use of illegal or dangerous substance because the temperaturerelated association might induce impulsivity which in turn would make consumers engage in undesirable behaviors with perceived immediate benefits. Thus, it may be important to reconsider pictures or words that are related to hot tem- peratures in such advertisements, in order to avoid undesirable consequences.

\subsection{Limitations and Future Research}

First, although I found that the psychological response of arousal did not affect willingness to pay and choices, one might argue that such a self-reported measure of arousal could not capture the sensitive change in participants' arousal states. Previous research also supports this concern, stating that a change in arousal states is normally unaccountable by a person's conscious awareness, and hence self-reported measures do not correlate with physiological measures ( $\mathrm{Li}$ 2008). To test the physiological response, future research may need to include a more reliable measure such as skin conductance responses (Khalfa et al. 2002: Lang et al. 1993).

Second, in this research, I did not directly test the effect of cognitive association between temperature and impulsivity on impulsive behaviors. One way to directly test for the effect would be to strengthen the association through the rehearsal of word pairs such as hot/desire or hot/urge and see if the effect gets stronger. The enhanced cognitive association may result in more impulsive behavior tendencies.

Third, metaphors have been typically considered unidirectional (Bargh 2006: Lakoff and Johnson 1980): concepts learned earlier in life, such as heat, should prime more abstract concepts such as impulsivity. However, recent research suggests 
that abstract concepts (e.g., social isolation and moral purity) can activate concrete concepts (coldness of room temperature and bodily purity) (Zhong and Leonardelli 2008: Zhong and Liljenquist 2006), in contrast to earlier research. Given the fact that some metaphoric relationships are bidirectional, the results of the current paper can be extended by testing the existence of an 'impulsivity-hot' link. In other words, it is worth testing whether individuals' impulsive behaviors can cause them to feel hot.

In conclusion, given that temperature is such a pervasive part of our daily lives, the temperature effects reported in this research are operative in a variety of consumer contexts. At the same time, this paper raises several important questions for future research. The answers to these questions are crucial in gaining a more comprehensive understanding of the effects of temperature and related concepts on consumer behavior and marketing in general.

〈Recieved August 13. 2012〉

〈Revised September 12. 2012〉

〈Accepted September 17. 2012〉

\section{References}

Ainslie, George (1975), "Specious Reward: A Behavioral Theory of Impulsiveness and Impulse Control," Psychological Bulletin, 82 (4), 463-95.
Amorim, Michel-Ange, Brice Isableu, and Mbhamed Jarraya (2006), "Embodied Spatial Transformations: Body Analogy for the Mental Rotation of Objects," Journal of Experimental Psychology, 135 (3), 327-47.

Bargh, John A. (2006), “What Have We Been Priming All These Years? on the Development, Mechanisms, and Ecology of Nonconscious Social Behavior," European Journal of Social Psychology, 36 (2), 147-68.

Barratt, Ernest S. (1985), "Impulsiveness Defined within a Systems Model of Personality," in Advances in Personality Assessment, eds. Charles D. Spielberger and James N. Butcher, Hillsdale, NJ: Lawrence Erlbaum. Barsalou, Lawrence W. (1999), "Perceptual Symbol Systems," Behavioral and Brain Sciences, 22 (August), 577-660. (2008), "Grounded Cognition," Annual Review of Psychology, 59 (1), 617-45.

Baumeister, Roy F. (2002), "Yielding to Temptations: Self-Control Failure, Impulsive Purchasing, and Consumer Behavior," Journal of Consumer Research, 28 (March), 670-76.

Baumeister, Roy F. and Todd. F. Heatherton (1996), "Self-Regulation Failure: An Overview," Psychosocial Inquiry, 7 (1), 1-15.

Beilock, Sian L. and Lauren E. Holt (2007), "Embodied Preference Judgments: Can Likeability Be Driven by the Motor System," Psychological Science, 18 (1), 51-7.

Bergh, Bram Van Den, Siegfried Dewitte, and 
Luk Warlop (2008), "Bikinis Instigate Generalized Impatience in Intertemporal Choice," Journal of Consumer Research, 35 (June). 85-97.

Bushman. Brad, J. and Craig A. Anderson (2001), "Is It Time to Pull the Plug on the Hostile versus Instrumental Aggression Dichotomy?" Psychological Review, 108 (1). 273-79.

Buss, Arnold H. and Robert Plomin (1975), A Temperament Theory of Personality Development, New York: Wiley.

Carver, Charles S. (2005), "Impulse and Constraint: Perspectives from Personality Psychology. Convergence with Theory in Other Areas, and Potential for Integration," Personality and Social Psychology Review, 9 (4). 312-33.

Dijksterhuis, Ap, Jesse Preston, Daniel M. Wegner, and Henk Aarts (2008), "Effects of Subliminal Priming of Self and God on self-attribution of Authorship for Events," Journal of Experimental Social Psychology, $44,2-9$.

Epstein, Seymour (1994), "Integration of the Cognitive and the Psychodynamic Unconscious," American Psychologist, 49 (8), 709-24.

Evenden, John L. (1999), "Varieties of Impulsivity." Psychopharmacology, 146 (4), 348-61.

Eysenck, Hans J. (1993), "The Nature of Impulsivity," in The Impulsive Client: Theory, Research, and Treatment. eds.. William G. McCown, Judith L. Johnson, and Myrna
B. Shure Washington, DC: American Psychological Association, 57-69.

Eysenck, Sybil B, and Hans J. Eysenck (1978). "Impulsiveness and Venturesomeness: Their Position in a Dimensional System of Personality Description," Psychological Reports, 43 (3), 1247-255.

Frederick, Shane (2005), "Cognitive Reflection and Decision Making," Journal of Economic Perspectives, 19 (4), 25-42.

Gallese, Vittorio and George Lakoff (2005). "The Brain's Concepts: The Role of the Sensory-Motor System in Conceptual Knowledge," Cognitive Neuropsychology, 22 (May). 455-79.

Glenberg, Arthur M. (1997), "What Memory Is For," Behavioral and Brain Sciences, 20 (1), 1-55.

Hoch, Stephen J, and George Loewenstein (1991), "Time-Inconsistent Preferences and Consumer Self-Control," Journal of Consumer Research, 17 (March), 492-507.

Hofmann, Wilhelm, Malte Friese, and Reinout W. Wiers (2008), "Impulsive versus Reflective Influences on Health Behavior: A Theoretical Framework and Empirical Review," Health Psychology Review, 2 (2). 111-37.

Holbrook, Morris B. and Elizabeth C. Hirschman (1982). "The Experiential Aspects of Consumption: Consumer Fantasies, Feelings, and Fun," Journal of Consumer Research, 9 (September), 132-40. 
Hsee, Christopher K. and Yuval Rottenstreich (2004), "Music, Pandas, and Muggers: On the Affective Psychology of Value," Journal of Experimental Psychology: General, 133 (1), $23-30$.

Jostmann, Nils B., Daniel Lakens, and Tomas W. Schubert (2009), "Weight as an Embodiment of Importance," Psychological Science, 20 (9), 1169-174.

Kacen, Jacqueline J. and Julie Anne Lee (2002), "The Influence of Culture on Consumer Impulsive Buying Behavior," Journal of Consumer Psychology, 12 (2), 163-76.

Kahneman, Daniel (2003), "A Perspective on Judgment and Choice: Mapping Bounded Rationality," American Psychologist, 58 (9). 697-720.

Kahneman, Daniel and Shane Frederick (2002). "Representativeness Revisited: Attribute Substitution in Intuitive Judgment," in Heuristics and Biases: The Psychology of Intuitive Judgment, ed. Thomas Gilovich, Dale Griffin, and Daniel Kahneman, 49-81. New York: Cambridge University Press.

Khalfa, Stéphanie, Peretz Isabelle, Blondin JeanPierre, and Robert Manon (2002), "EventRelated Skin Conductance Responses to Musical Emotions in Humans," Neuroscience Letters, 328 (2), 145-49.

Lakoff, George and Mark Johnson (1980), $\mathrm{Me}^{-}$ taphors We Live by, Chicago, IL: University of Chicago Press.

Lang, Peter J., Mark K. Greenwald, Margaret
M. Bradley, and Alfons O. Hamm (1993), "Looking at Pictures: Affective, Facial, Visceral, and Behavioral Reactions," Psychophysiology, 30 (3), 261-73.

Langewisch, Mark W. J. and G. Ron Frisch (1998), "Gambling Behavior and Pathology in Relation to Impulsivity, Sensation Seeking, and Risky Behavior in Male College Students," Journal of Gambling Studies, 14 (3), 245-62.

Li, Xiuping (2008), "The Effects of Appetitive Stimuli on Out-of-Domain Consumption Impatience," Journal of Consumer Research, 34 (February), 649-56.

Loewenstein, George (1996), "Out of Control: Visceral Influences on Behavior," Organizational Behavior and Human Decision Processes, 65 (3), 272-92.

Metcalfe, Janet and Walter Mischel (1999), "A Hot/Cool-System Analysis of Delay of Gratification: Dynamics of Willpower," Psychological Review, 106 (1), 3-19.

Monterosso, John and George Ainslie (1999), "Beyond Discounting: Possible Experimental Models of Impulse Control," Psychopharmacology (Berl), 146, 339-47.

Neidenthal, Paula M., Lawrence W. Barsalou, Piotr Winkielman, Silvia Krauth-Gruber, and Francois Ric (2005), "Embodiment in Attitudes, Social Perception, and Emotion," Personality and Social Psychology Review, 9 (3), 184-211.

Nelson, Leif D. and Joseph P. Simmons (2009), 
"On Southbound Ease and Northbound Fees:

Literal Consequences of the Metaphoric Link between Vertical Position and Cardinal Direction," Journal of Marketing Research, 46 (December), 715-24.

Park, Sehoon and Moon-Yong Kim (2010), "The Influence of Purchase Quantity and Timing on Consumer Choice between Hedonic and Utilitarian Options," Journal of Korean Marketing Association, 25 (3), 137-168.

Peters, Ellen, Daniel Vastfjall, Tommy Garling, and Paul Slovic (2006), "Affect and Decision Making: A Hot Topic," Journal of Behavioral Decision Making, 19, 79-85.

Porteus, Stanley (1965), The Maze Test and Clinical Psychology, Palo Alto, CA: Pacific Books.

Puri, Radhika (1996), “Measuring and Modifying Consumer Impulsiveness: A Cost-Benefit Accessibility Framework," Journal of Consumer Psychology, 5 (2), 87-113.

Romer, Daniel (2010), “Adolescent Risk Taking, Impulsivity, and Brain Development: Implications for Prevention," Developmental Psychobiology, 52 (3), 263-76.

Rook, Dennis (1987), "The Buying Impulse." Joumal of Consumer Research, 14 (September). 189-99.

Rook, Dennis and Robert J. Fisher (1995), "Normative Influences on Impulsive Buying Behavior," Journal of Consumer Research, 22 (December), 305-13.

Rook, Dennis and Stephen J. Hoch (1985), “Con- suming Impulses", in Advances in Consumer Research, Volume 12, eds. Elizabeth C. Hirschman and Moris B. Holbrook, Provo, UT : Association for Consumer Research, Pages: 23-7.

Salovey, Peter and Deborah Birnbaum (1989), "Influence of Mood on Health-Relevant Cognitions," Journal of Personality and Social Psychology, 57 (3), 539-51.

Srull, Thomas K. and Robert S. Wyer (1979). "The Role of Category Accessibility in the Interpretation of Information about Persons: Some Determinants and Implications," Journal of Personality and Social Psychology, 37 (10), 1660-172.

Stanovich, Keith E. and Richard F. West (2000), "Individual Differences in Reasoning: Implications for the Rationality Debate?" Behavioral and Brain Sciences, 23 (5), 645-65. Strahan, Erin J., Steven J. Spencer and Mark P. Zanna (2002), "Subliminal Priming and Persuasion: Striking While the Iron is Hot," Journal of Experimental Social Psychology, 38, 556-568.

Vohs, Kathleen D. and Ronald J. Faber (2007), "Spent Resources: Self-Regulatory Resource Availability Affects Impulse Buying," Journal of Consumer Research, 33 (March), 537-47. Williams, Lawrence E. and John A. Bargh (2008), “Experiencing Physical Warmth Promotes Interpersonal Warmth," Science, 322 (5901), 606-07.

Zhong, Chen-Bo and Geoffrey J. Leonardelli 
(2008), "Cold and Lonely: Does Social Exclusion Literally Feel Cold?" Psychological Science, 19 (9), 838-42.

Zhong, Chen-Bo and Katie Liljenquist (2006), "Washing Away Your Sins: Threatened Morality and Physical Cleansing," Science, 313 (5792), 1451-452.
Zuckerman, Marvin (1994), Behavioral Expressions and Biosocial Bases of Sensation Seeking, Cambridge, England: Cambridge University Press.

The American Heritage Dictionary of the English Language, 2000

Collins English Dictionary- Complete and Unabridged Sixth Edition 2003. 